\title{
Cisplatin cytotoxicity is increased by mifepristone in cervical carcinoma: An in vitro and in vivo study
}

\author{
RAFAEL JURADO, ANGELICA LOPEZ-FLORES, \\ AARON ALVAREZ and PATRICIA GARCÍA-LÓPEZ \\ Laboratorio de Farmacología, Subdirección de Investigación Básica, \\ Instituto Nacional de Cancerología (INCan), México D.F., México
}

Received June 3, 2009; Accepted July 10, 2009

DOI: 10.3892/or_00000560

\begin{abstract}
We investigated the ability of mifepristone, an anti-progestin drug, to modulate the cytotoxic effect of cisplatin in two cervical cancer cell lines and in human xenograft cervical tumors. The effect of cisplatin alone or combined with mifepristone on cellular proliferation was studied with the XTT assay which use a tetrazolium dye \{sodium3'-[1-(phenylamino-carbonyl)-3,4-tetrazolium],XTT\}. Before and after treatment with mifepristone, the intracellular accumulation of cisplatin in cancer cells and tumors of mice was evaluated by HPLC. The expression of Bcl-2 and Bax genes was also assessed by a reverse transcriptase polymerase chain reaction (RT-PCR) and Western blotting. In addition, single agents and combination treatment in vivo studies were performed with the xenograft cervical model. Tumor measurements were carried out weekly. Analysis of the data by the isobologram method shows a synergistic antiproliferative effect produced by the combination of mifepristone with cisplatin only in the HeLa cervical cancer cell line but not in CaSki cells. The effect of mifepristone on cytotoxicity of cisplatin could be mediated, at least partially, by an increase of intracellular cisplatin accumulation, but not by changes in Bcl-2/Bax gene relation expression in these cells. In vivo studies showed that the combination of these agents has a significant antitumor activity against HeLa xenograft tumors. Our results suggest that mifepristone can improve the efficacy of the antiproliferative effect of cisplatin in vitro and in vivo. This anti-hormonal drug therapy may be a useful candidate for further evaluation in combination with other
\end{abstract}

Correspondence to: Dr Patricia García-López, Laboratorio de Farmacología, Subdirección de Investigación Básica, Instituto Nacional de Cancerología (INCan), Av. San Fernando 22, Tlalpan 14000, Apartado Postal 22026, México D.F., México

E-mail: pgarcia_lopez@yahoo.com.mx garcia_lopez@salud.gob.mx

Key words: antihormonals, cervical cancer, cisplatin, drug synergism, mifepristone antineoplastic drugs in the treatment of cancer, particularly with cisplatin.

\section{Introduction}

Cervical carcinoma is a major gynecological cancer in several low-income countries. Although routine screening programs for detection have been implemented since 1975, an increased rate of new cases has also been found $(1,2)$. Human papillomavirus (HPV) is known etiological factor for $99 \%$ of cervical cancers (3). Additionally, it has been predicted that within 10 years, if there were no medical intervention, $66 \%$ of all dysplasia would progress to carcinoma in situ. It is important to bear these data in mind to stimulate the search for new alternatives for cervical cancer treatment.

Cisplatin and its derivatives are important drugs in cervical cancer therapy $(4,5)$. However, the administration of cisplatin is associated with serious side effects, including nephrotoxic and neurotoxic events (6). Furthermore, in advanced stages of this pathology intrinsic resistance to cisplatin is developed due to several factors as a diminished intratumoral accumulation of the drug or less apoptotic response. Therefore, new agents or new regimens in combination with cisplatin are being sought in order to increase antitumoral activity and decrease adverse effects.

Among the chemosensitizer drugs, antiestrogens such as tamoxifen and ICI 182,780 (7-9), and antiprogestins such as mifepristone have been used to modulate the cytotoxic activity of doxorubicin, paclitaxel, cisplatin and other antineoplastic agents, principally in hormone-dependent cancers such as breast, prostate and ovarian cancers. However, the role of the antihormonals in cervical carcinoma has rarely been studied.

It is known that the normal cervix responds to steroid sex hormones, but that cervical carcinoma does not respond to antihormonal therapy. Previously we demonstrated that the antiestrogen ICI 182,780 combined with cisplatin was able to enhance cytotoxicity in three cervical cancer cell lines (HeLa, SiHa and CaSki) (10). We found a synergistic cytotoxic effect more evident in HeLa cells, with approximately 18 times higher potency in comparison to cisplastin alone. In SiHa and CaSki cell lines this effect was up to 4.5-fold greater. 
The activity of mifepristone on the cytotoxicity of cisplatin in cervical cancer treatment has not been explored. Therefore, the aim of the present study was to investigate the ability of mifepristone to modulate the cytotoxic effect of cisplatin in two cervical cancer cell lines and in tumor growth of xenograft cervical cancer and its probable mechanism of action.

\section{Materials and methods}

Drugs and reagents. Cisplatin, chloroform, trypsin, sodium chloride and sodium diethyldithiocarbamate (DDTC) were obtained by Sigma Chemicals Co. (St. Louis, MO, USA). Methanol, acetonitrile and ethyl ether of chromatographic grade, were obtained from Merk (Darmstadt, Germany). Dulbecco's modified Eagle's medium (DMEM), FCS (fetal calf serum), EDTA (ethylenediaminetetracetic acid), Tris and SDS were obtained by Gibco, BRL (Grand Island, NY, USA). High-quality water employed to prepare solutions was obtained through of a Milli-Q Reagent Water System [Continental Water Systems (El Paso, TX, USA)]. TaqDNA polymerase was purchased from Invitrogen (Carlsbad, CA, USA).

Solutions. Stock solutions (1 mg/ml) of cisplatin were prepared in saline solution. Mifepristone was reconstituted in absolute ethanol (stock solution). All standard solutions were stored at $-20^{\circ} \mathrm{C}$.

Animals. Female Nude mice (National Institute of Nutrition, Mexico City, Mexico) between 6-8 weeks of age were kept in a pathogen-free environment and fed ad libitum. The protocol for the care and use of the animals was approved by the ethics committee of the National Cancer Institute (Mexico City, Mexico).

Cell cultures. The HeLa and CaSki human cervical cancer cell lines were obtained from ATCC (Rockville, MD, USA), and were routinely maintained as monolayer in DMEM supplemented with $10 \%$ fetal bovine serum, and incubated at $37^{\circ} \mathrm{C}$ in a $5 \% \mathrm{CO}_{2}$ atmosphere and high humidity. Cells were harvested with $0.025 \%$ trypsin and $1 \mathrm{mM}$ EDTA.

Growth inhibition experiments. The effect of Mifepristone on proliferation of cells exposed to cisplatin was evaluated using the XTT assay \{sodium 3'-[1-(phenylamino-carbonyl)-3,4tetrazolium]-bis\}; Roche Molecular Biochemicals (Mannheim, Germany) (11). The assay is based on the cleavage of the yellow tetrazolium salt XTT to form an orange formazan dye by metabolically active cells. The procedure was as follows. Cells were seeded into 96-well plates; Costar (Cambridge, MA, USA) at a density of $6 \times 10^{3}$ viable cells per well in $100 \mu 1$ culture medium. At the end of treatment with cisplatin alone or the combination of cisplatin plus mifepristone, $50 \mu 1$ XTT was added to each well (final concentration $0.3 \mathrm{mg} / \mathrm{ml}$ ), followed by incubation for $4 \mathrm{~h}$ in a humidified atmosphere containing $5 \% \mathrm{CO}_{2}$ at $37^{\circ} \mathrm{C}$. The absorbance of the samples was measured spectrophotometrically at $492 \mathrm{~nm}$ using a microtiter plate ELISA reader; Multiskan MCC Termo Electron Corp. (Vantaa, Finland).

Treatments with mifepristone and cisplatin. The cells were conditioned for 4 days with $10 \mu \mathrm{M}$ mifepristone. The final volume was $100 \mu 1$ per well. Control cells were exposed only to vehicle (the final ethanol concentration never exceeded $1 \%$ in treated and control samples). At the end of the exposure period, the culture medium was removed and fresh medium with various amounts of cisplatin $(0.1-330 \mu \mathrm{M})$ plus mifepristone $10 \mu \mathrm{M}$ was added for $4 \mathrm{~h}$. After simultaneous and individual exposure to the drugs, the cells were then cultivated in fresh medium for 20 additional hours. At the end of the treatment with cisplatin alone or the combination of cisplatin plus mifepristone, cell proliferation was evaluated using the XTT assay.

The mean concentration in each set of three or four wells was determined in triplicate. The percentage growth inhibition was calculated and $\mathrm{IC}_{50}$ values (concentration of drug to achieve $50 \%$ growth inhibition) were obtained graphically from the survival curves.

Data analysis of drug combination. Synergism or additivity was determined by calculating the combination index (CI) using the equation: $\mathrm{CIx}=\left(\mathrm{D}_{1} / \mathrm{Dx}_{1}\right)+\left(\mathrm{D}_{2} / \mathrm{Dx}_{2}\right)+\alpha\left(\mathrm{D}_{1}\right)\left(\mathrm{D}_{2}\right) /$ $\left(\mathrm{Dx}_{1}\right)\left(\mathrm{Dx}_{2}\right)$. CIx represents the CI value for $\mathrm{x} \%$ effect, $\mathrm{Dx} \mathrm{x}_{1}$ and $\mathrm{Dx}_{2}$ represent the doses of agents 1 and 2 required to exert $\mathrm{x} \%$ effect alone, and $\mathrm{D}_{1}$ and $\mathrm{D}_{2}$ represent the doses of agents 1 and 2 that elicit the same $\mathrm{x} \%$ effect in combination with the other agent, respectively. The factor $\alpha$ indicates the type of interaction: $\alpha=0$ for mutually exclusive drugs (similar mechanisms of action), and $\alpha=1$ for mutually non-exclusive drugs (independent modes of action) (12); the equation was resolved for $\alpha=1$. $\mathrm{CI}=1$ indicates additivity, $\mathrm{CI}<1$ synergism and $\mathrm{CI}>1$ antagonism.

Expression of Bcl-2 and Bax genes. The cells were treated as stated before and the total RNA was isolated from each cell line. The total RNA extraction was performed using the TRIzol methodology (Gibco, BRL). RNA was quantified through the spectrophotometer assay and the RNA content of the samples was normalized before the RT-PCR (Reverse transcriptase-polymerase chain reaction) assay.

The Bcl-2 and Bax gene expression was analyzed through the reverse transcription of the RNA, transcribing it to cDNA and then amplifying it using the polymerase chain reaction. To assess the initial quantity and integrity of the RNA, we used the constitutive gene GAPDH.

The primer sequences for Bcl-2 were 5'-CCC TCC AGA TAG CTC ATT-3', and 5'-CTA GAC AGA CAA GGA AAG-3'. The Bax primer secuences were 5'-ATG GAC GGG TCC GGG GAG-3', and 5'-TCA GAA AAC ATG TCA GCT GCC-3'. The GAPDH primers were 5'-CCA CCC ATG GCA AAT TCC ATG GCA-3' and 5'-TCT AGA CGG CAG GTC AGG TCC ACC-3'. All primers were synthesized by Gibco, BRL Co.

The 500 ng of initial RNA were transcribed with oligo(dt) and the aviary myeloblastosis reverse transcriptase from Invitrogene Co. The transcription was performed during $60 \mathrm{~min}$ at $50^{\circ} \mathrm{C}$. The cDNA amplification was performed in the Thermo Hybaid PCR sprint termocycler (Termo Electron Corp.) with a hot start at $94^{\circ} \mathrm{C}$ for $2 \mathrm{~min}, 32$ cycles at $94^{\circ} \mathrm{C}$ for $45 \mathrm{sec}, 60^{\circ} \mathrm{C}$ for $45 \mathrm{sec}, 72^{\circ} \mathrm{C}$ for $45 \mathrm{sec}$, a final extension of $7 \mathrm{~min}$ at $72^{\circ} \mathrm{C}$ was realized. 
Prior to PCR, we made sure that with the number of cycles used, the products were still in the exponential part of the curve for all the primers. This means that the product quantity is in direct proportion to each gene expression.

The reaction products of the samples were then electrophoresed in $1 \%$ agarose gel. The bands were stained with etidium bromide and UV analyzed. Densitometric measure of the corresponding areas was obtained. Both areas Bcl-2 and Bax were normalized to the corresponding GAPDH (charge control band) by the operation Bcl-2/GAPDH and Bax/ GAPDH, and then charted. Three independent experiments were performed for each cell line.

Bcl-2 Western blot analysis. After exposure to cisplatin $(33 \mu \mathrm{M})$, or cisplatin plus mifepristone $(10 \mu \mathrm{M})$ the proteins were extracted from HeLa and CaSki cells. Protein extraction was performed for $30 \mathrm{~min}$ on ice in RIPA buffer containing $250 \mathrm{mM} \mathrm{NaCl}, 50 \mathrm{mM}$ Tris, $0.1 \% \mathrm{SDS}$, and protease inhibitors. Proteins were quantitated using the bicinconinic acid test (Sigma Aldrich, Co., St. Louis, MO, USA), and the protein concentration was normalized for all samples. The samples were run in a polyacrylamide electrophoresis gel (PAGE), and then the gel was transferred to a PVDF membrane (Millipore, Bedford, MA, USA) and incubated with anti-bcl-2 and anti-ß-actin monoclonal antibodies (Santa Cruz Biotechnology, Inc., Santa Cruz, CA, USA). Later a peroxidated anti-IgG was attached and the union was revealed with the chemiluminescent ECL Western blotting kit, the image was stored on hyperfilm (Amersham Biosciences Co., Buckinhamshire, UK).

The bands were densitometrically measured and the area of the corresponding band was obtained. The Bcl-2 area was normalized to the $\beta$-actin (charge control band) by the ratio Bcl-2/actin.

Intracellular cisplatin accumulation. HeLa and CaSki human cervical cancer cells were seeded at $1 \times 10^{5}$ cell/ml on a $75 \mathrm{~cm}^{2}$ tissue culture flask (Costar) in DMEM supplemented with $10 \% \mathrm{FCS}$, and incubated at $37^{\circ} \mathrm{C}$ in $5 \% \mathrm{CO}_{2}-95 \%$ air at high humidity. After $24 \mathrm{~h}$ the medium was replaced with fresh medium containing cisplatin alone for $4 \mathrm{~h}$ to a final concentration of $33 \mu \mathrm{M}$ or in combination with mifepristone $(10 \mu \mathrm{M})$. As a control non-exposed cells were treated with vehicle and cultured for the same period. At the end of the cisplatin incubation, the cells were then washed in situ four times with ice-cold PBS and harvested with $0.025 \%$ trypsin and $1 \mathrm{mM}$ EDTA. After that they were counted with a haemocytometer and lysed with buffer (Tris $100 \mathrm{mM}$, EDTA $5 \mathrm{mM}, \mathrm{NaCl} 200 \mathrm{mM}$, SDS $0.2 \%$, at $\mathrm{pH} 8.0$ ) for $3 \mathrm{~h}$ at $55^{\circ} \mathrm{C}$. The intracellular concentration of cisplatin was estimated by the High Performance Liquid Chromatographic (HPLC) method previously validated and reported (13). Briefly, the homogenate was ultrafiltered and derivatized with DDTC in $0.1 \mathrm{~N} \mathrm{NaOH}$. Samples were incubated in a $37^{\circ} \mathrm{C}$ water bath for $15 \mathrm{~min}$, and then extracted with $80 \mu \mathrm{l}$ chloroform by vortexing at maximal speed for $1 \mathrm{~min}$. The two layers were separated by centrifugation at $10000 \mathrm{rpm}$ for $5 \mathrm{~min}$. Finally, $20 \mu 1$ of chloroform layer was injected into the chromatographic system. Before the HPLC assay, the samples were protein quantified using the bicinconinic acid test, and the protein concentration was normalized for all samples.

In vivo evaluation of mifepristone and cisplatin in human cervix tumor xenografts. The animals were implanted subcutaneously with $6 \times 10^{6} \mathrm{HeLa}$ cells in a flank. Once tumors were $\sim 5 \times 5 \mathrm{~mm}$, the animals were pair-matched into treatment and control groups. Each group consisted of 8 tumor-bearing mice. The intraperitoneal administration of drugs or vehicle began on day 0 . Cisplatin, as a single agent, was administered intraperitoneally at a dose of $3 \mathrm{mg} / \mathrm{kg}$ daily on days 1 through 3 ; the dose of mifepristone, as a single agent, was $2 \mathrm{mg} / \mathrm{kg} /$ day subcutaneously for 3 days; in the combination study, the mice concurrently received cisplatin on the same schedule, and mifepristone at the same dose 3 days previous to the administration of cisplatin. The control animals received only the vehicle. After administration of the drugs, mice were weighed and the tumors were measured with a caliper twice weekly. The tumor weight was calculated using the formula: weight $(\mathrm{mg})=$ width $(\mathrm{mm})^{2} \times$ length $(\mathrm{mm})$. Experiment was conducted for 74 days, after which time all animals were weighed and humanely euthanized.

Intratumor cisplatin accumulation. When all tumors had reached a measurable size $(\sim 5 \times 5 \mathrm{~mm})$ eight mice were assigned to each of two groups. The groups were treated as described, $24 \mathrm{~h}$ after the last cisplatin administration the mice from the both groups were anaesthetized with ethyl ether and the tumors were immediately removed, weighed, frozen and stored at $-70^{\circ} \mathrm{C}$ until analyzed. Tumors from untreated animals were removed in the same way. In order to extract cisplatin, the tumors were lysed with $450 \mu \mathrm{l}$ of buffer (Tris $100 \mathrm{mM}$, EDTA $5 \mathrm{mM}, \mathrm{NaCl} 200 \mathrm{mM}$, SDS 0.2\%, at pH 8.0) for $8 \mathrm{~h}$ at $55^{\circ} \mathrm{C}$. The homogenate was ultrafiltrated, derivatizated with $20 \mu \mathrm{l}$ of DDTC and extracted with $160 \mu \mathrm{l}$ of chloroform. Finally, $20 \mu 1$ of the chloroform layer was injected into a chromatographic system and the cisplatin concentration was determined using a method previously validated and reported (13).

In vivo pharmacokinetics. We designed a pharmacokinetic assay in nude mice. The animals were administered with cisplatin alone or in combination with mifepristone at the doses previously described. The mice were sequentially sacrificed at $0,5,10,15,20,30,60 \mathrm{~min}$ after injection. The blood samples were collected in heparinized tubes and the plasma was ultrafiltered, frozen and stored at $-20^{\circ} \mathrm{C}$ until analysis. The cisplatin concentrations were quantified following the methodology previously described for cells and tumors. Pharmacokinetic parameters were calculated with WIN-NONLIN software.

Chromatographic conditions for determination of cisplatin. The chromatographic system consisted of a $650 \mathrm{E}$ solvent delivery (Waters Assoc., Milford, MA, USA), a 20- $\mu 1$ loop injector (Rheodyne, Cotati, CA, USA), and an UV detector 486. Analyses for cisplatin were carried out on a 150x3.9 mm I.D. Symmetry C18 column of $4 \mu \mathrm{m}$ particle size; column elution was carried out at $23^{\circ} \mathrm{C}$ using a mixture of water/ methanol/acetonitrile as mobile phase at a fixed flow rate of $1.6 \mu \mathrm{m} / \mathrm{min}$. The detection was performed at $254 \mathrm{~nm}$. 
A

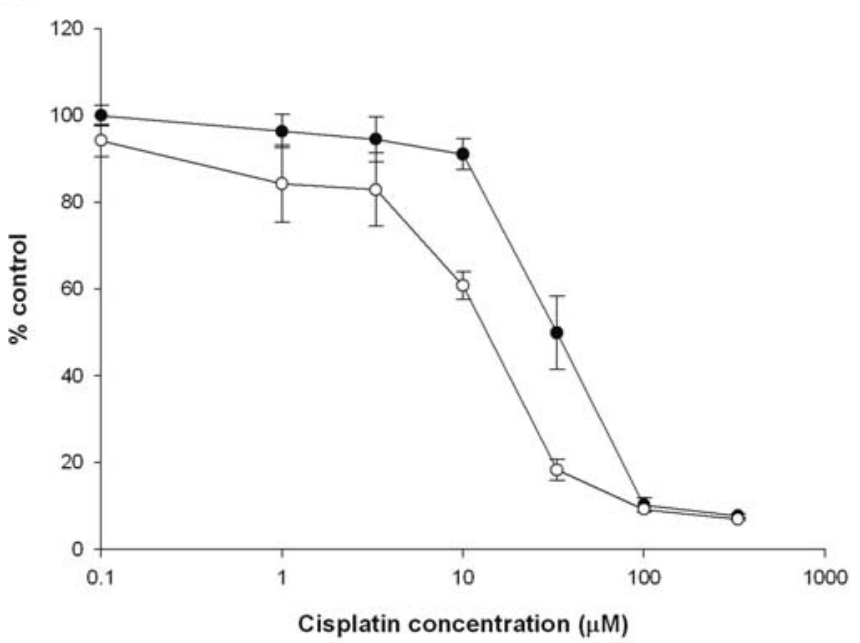

B

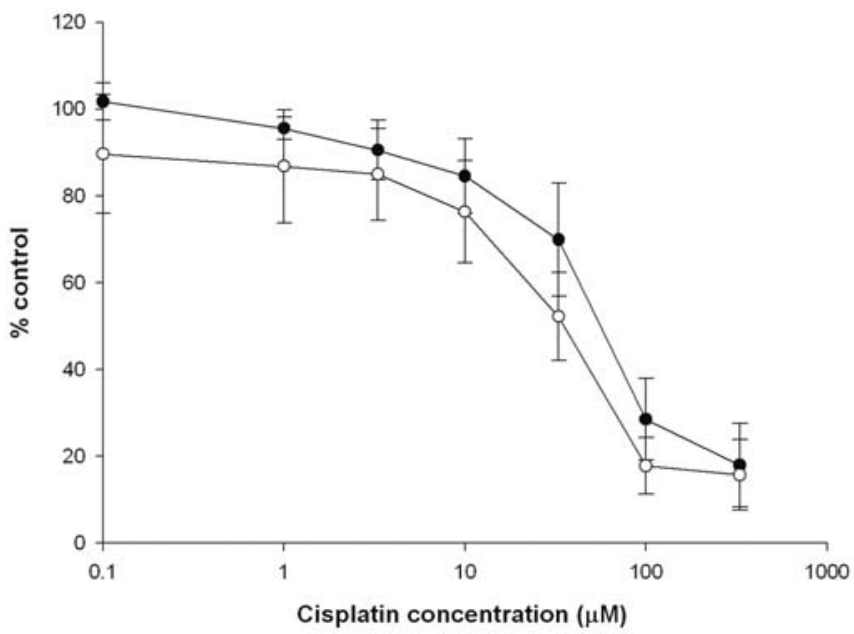

Figure 1. Representative growth inhibition curves of cisplatin alone (closed circles) and in combination with mifepristone $10 \mu \mathrm{M}$ (open circles), in HeLa (A) and CaSki (B) cell lines. Cells were exposed to mifepristone for 4 days, followed by exposure to cisplatin for $4 \mathrm{~h}$. After treatment, the effect was evaluated at $24 \mathrm{~h}$. All growth inhibition assays were repeated in triplicate in at least three independent experiments. Values represent the means \pm standard error of mean (SEM).

Statistical analysis. Statistical analysis of the data was performed using the Student's t-test with SigmaStat software. $\mathrm{P}<0.05$ was considered statistically significant.

\section{Results}

Growth inhibition experiments. Cytotoxicity is expressed as percentage growth inhibition of HeLa and CaSki cells treated for $4 \mathrm{~h}$ with either cisplatin alone or in combination with mifepristone. Cell growth was evaluated after 4 days of exposure to mifepristone at $10 \mu \mathrm{M}$, a concentration close to the plasma concentration achievable in humans (Fig. 1). The antiproliferative effect of cisplatin was potentiated when administered in combination with mifepristone in HeLa cells (Fig. 1A). However, in CaSki cells, no synergistic effect was observed (Fig. 1B). The $\mathrm{IC}_{50}$ of cisplatin in combination with mifepristone was lower $(14.2 \mu \mathrm{M})$ than that of cisplatin alone

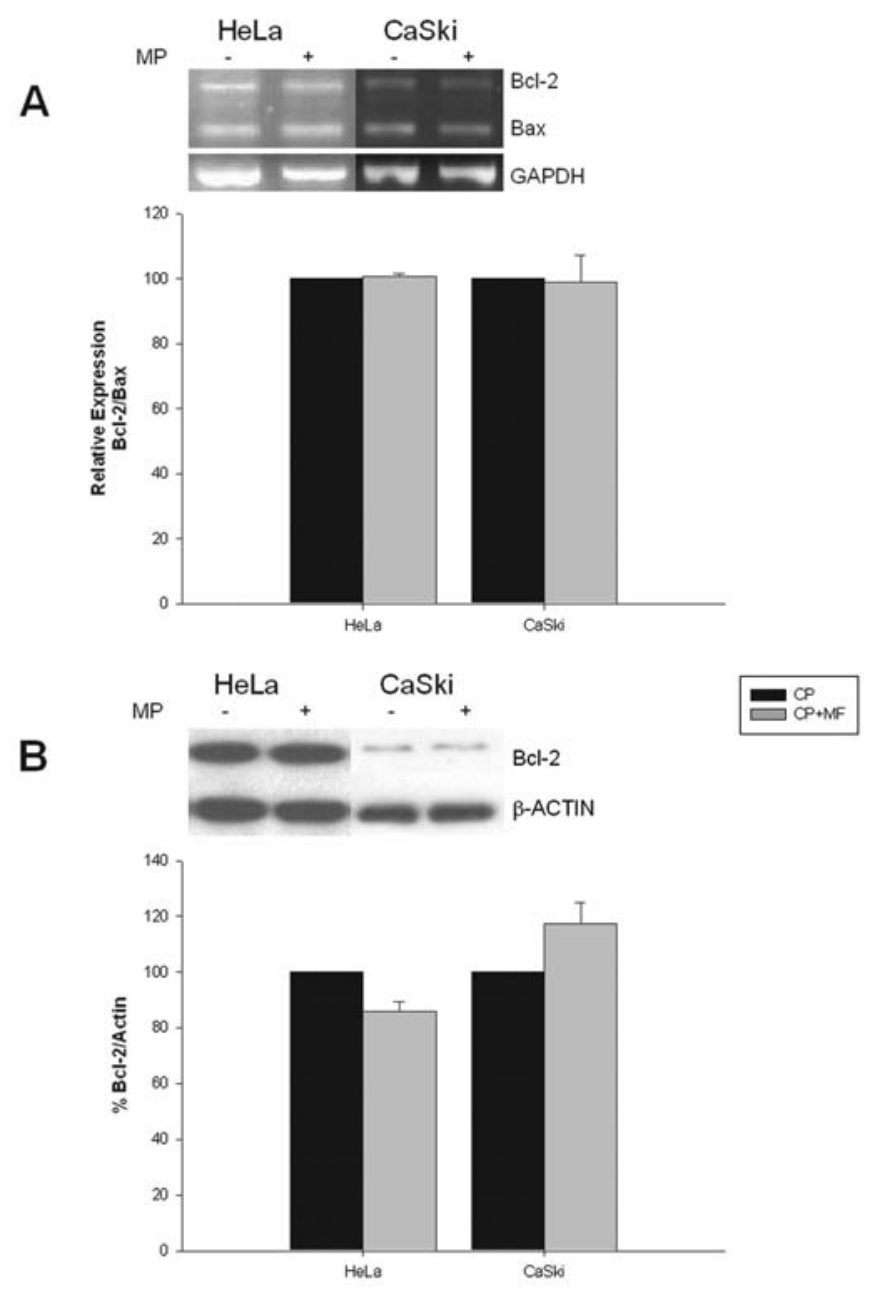

Figure 2. (A) RT-PCR analysis of Bcl-2 and Bax gene expression in HeLa and CaSki cells treated with cisplatin for $4 \mathrm{~h}$ in absence or presence of mifepristone $10 \mu \mathrm{M}$. Amplifying GAPDH RT-PCR products provided a control for the amount of intact RNA used in the reaction. Semi-quantitative analysis of the ratio $\mathrm{Bcl}-2 / \mathrm{Bax}$ gene expression to that of GAPDH. (B) Western blot analysis of Bcl-2 protein in cellular extracts of HeLa and CaSki cells. A representative result of three independent experiments is presented. Semi-quantitative analysis of the ratio Bcl-2/Bax gene expression to that of $\beta$-actin. The values are the means \pm SEM of three independent experiments.

$(34.2 \mu \mathrm{M})$ in HeLa cells with an approximately 2.5 -fold difference. To determine whether the combination effect of mifepristone and cisplatin in HeLa cells was synergistic or additive, the CI was determined using the equation given in Materials and methods. The CI obtained showed that the interaction of mifepristone and cisplatin was synergistic at a dose of 10,33 and $100 \mu \mathrm{M}$ of cisplatin (Table I). CaSki cells were more resistant to cisplatin alone $\left(\mathrm{CI}_{50}=55 \mu \mathrm{M}\right)$; the combination treatment did not resulted in any synergistic effect.

Bcl-2/Bax gene expression and Bcl-2 Western blot analysis in cells treated with mifepristone and cisplatin. In order to determine whether mifepristone inhibits apoptosis in cervical carcinoma cells by regulating antiapototic proteins, expression of $\mathrm{Bcl}-2 / \mathrm{Bax}$ was analyzed by RT-PCR and the $\mathrm{Bcl}-2$ protein production was analyzed by Western blotting (Fig. 2). In both HeLa and CaSki cell lines, Bcl-2/Bax expression was 
Table I. Synergistic antiproliferative effects of the combination of mifepristone and cisplatin in HeLa cells.

\begin{tabular}{|c|c|c|c|c|c|}
\hline $\begin{array}{c}\mathrm{CP}(\mu \mathrm{M}) \\
\left(\mathrm{D}_{1}\right)\end{array}$ & $\begin{array}{l}\text { Mifepristone }(\mu \mathrm{M}) \\
\qquad\left(\mathrm{D}_{2}\right)\end{array}$ & $\begin{array}{l}\mathrm{CP}(\mu \mathrm{M}) \\
\quad\left(\mathrm{Dx}_{1}\right)\end{array}$ & $\begin{array}{l}\text { Mifepristone }(\mu \mathrm{M}) \\
\qquad\left(\mathrm{Dx}_{2}\right)\end{array}$ & $\begin{array}{l}\text { Control growth } \\
(\mathrm{x} \%)^{\mathrm{b}}\end{array}$ & $\begin{array}{l}\text { Combination } \\
\text { index }(\mathrm{CIx})^{\mathrm{a}}\end{array}$ \\
\hline 0.1 & 10 & 2.6 & 1.17 & 95 & 8.5 \\
\hline 1.0 & 10 & 7.7 & 8.59 & 84 & 1.3 \\
\hline 3.3 & 10 & 10.3 & 9.77 & 83 & 1.3 \\
\hline 10 & 10 & 24.5 & 31.25 & 61 & $0.72 \mathrm{~s}$ \\
\hline 33 & 10 & 87.6 & $>100$ & 18 & $0.46 \mathrm{~s}$ \\
\hline 100 & 10 & 137.9 & $>100$ & 9 & $0.81 \mathrm{~s}$ \\
\hline 330 & 10 & 166 & $>100$ & 7 & 2.0 \\
\hline
\end{tabular}

${ }^{a} \mathrm{CIx}=\left(\mathrm{D}_{1} / \mathrm{Dx}_{1}\right)+\left(\mathrm{D}_{2} / \mathrm{Dx}_{2}\right)+\alpha\left(\mathrm{D}_{1}\right)\left(\mathrm{D}_{2}\right) /\left(\mathrm{Dx}_{1}\right)\left(\mathrm{Dx}_{2}\right)$, where CIx represents combination index for $\mathrm{x} \%$ effect. Dx 1 and Dx 2 are doses used of cisplatin $(\mathrm{CP})$ alone and mifepristone alone, respectively, required to exert $\mathrm{x} \%$ effect. $\mathrm{D}_{1}$ and $\mathrm{D}_{2}$ are doses of $\mathrm{CP}$ and mifepristone, respectively, used in combination that elicit the same $\mathrm{x} \%$ effect. ${ }^{\mathrm{b}}$ Mean values of three separate experiments performed in triplicate. $\mathrm{CI}=1$ indicates additivity, $\mathrm{CI}<1$ synergism and $\mathrm{CI}>1$ antagonism.

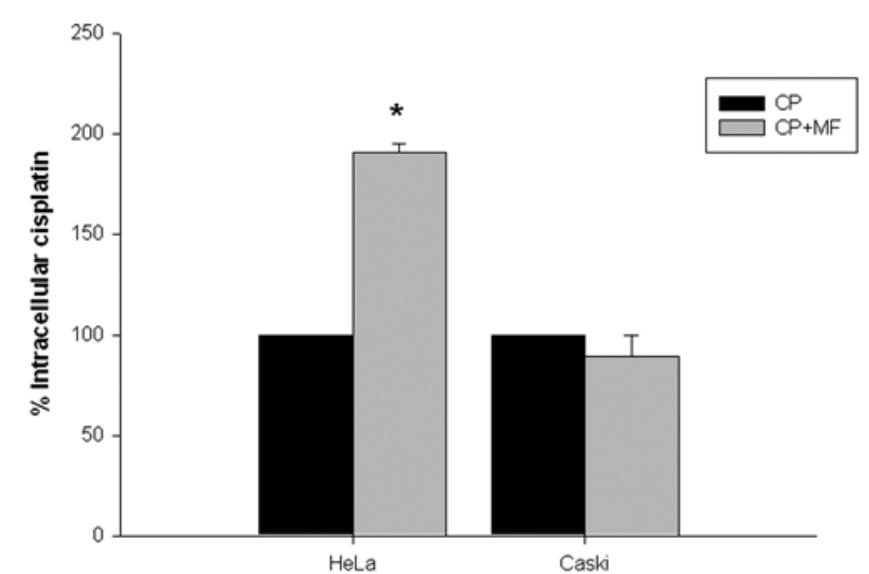

Figure 3. Effect of mifepristone on cisplatin accumulation in HeLa and CaSki cells. The intracellular cisplatin concentration was determined using a HPLC method as described in Materials and methods. The values are the mean $\pm \mathrm{SD}$ of three independent experiments. ${ }^{*} \mathrm{P}<0.05$.

not changed with cisplatin alone or in combination with mifepristone (Fig. 2A). The results were evaluated semiquantitatively by calculating the ratios of the expression of the Bcl-2 or Bax gene to that of GAPDH.

On the other hand, Western analysis in HeLa and CaSki cells demonstrated that protein levels of Bcl-2 levels were not significantly modified after treatment with cisplatin plus mifepristone in comparison to treatment with cisplatin alone (Fig. 2B).

Intracellular cisplatin accumulation. In order to assess another mechanism to explain the decreased proliferation rate in mifepristone treated cells, intracellular accumulation of cisplatin was measured in presence or absence of mifepristone in both cell lines. After treatment with mifepristone, the accumulation of intracellular cisplatin in HeLa cells was 2fold greater, representing a significant difference $(\mathrm{p}=0.009)$, compared with cisplatin alone from 0.79 to $1.52 \mu \mathrm{g} / \mathrm{mg}$ of protein (Fig. 3). In contrast, no significant modification in the cisplatin accumulation was observed in mifepristonetreated CaSki cells, from 1.30 to $1.18 \mu \mathrm{g} / \mathrm{mg}$ of protein $(\mathrm{p}=0.423)$.

Tumor growth evaluation after treatment with mifepristone and cisplatin in human cervix tumor xenografts. The results of studies with cisplatin alone and in combination with mifepristone in the cervix tumor xenograft models are shown in Fig. 4. We observed that with cisplatin alone there was a tumor growth inhibition compared with control group. However, the tumor weight loss was even more significant $(\mathrm{p}<0.05)$ with the combination regimen at the doses used, showing a decrease of $\sim 50 \%$ compared with the treatments alone by the end of the study (Fig. 4A).

Toxicity of treatments. The weight loss of animals treated with cisplatin alone was typically greatest on day 5 posttreatment $(18 \%)$, whereas for animals treated with the combination of cisplatin and mifepristone was greatest on day 5 at $14 \%$. In both groups the weight of the animals returned to the pretreatment values by the end of the study (Fig. 4B). In the case of the animals treated with mifepristone alone, no change in weight was observed, indicating clearly no differences in the systemic toxicity in any treatment group.

Intratumor cisplatin accumulation. The intratumoral cisplatin concentration was determined in mice treated with cisplatin alone or in combination with mifepristone. The cisplatin levels increased significantly $(\mathrm{p}<0.05)$, by $\sim 50 \%$, in the tumors of mice treated with the combination treatment $(1.38 \mu \mathrm{g} / \mathrm{mg}$ of protein) compared to the group that received only cisplatin (0.93 $\mu \mathrm{g} / \mathrm{mg}$ of protein) (Fig. 5).

In vivo pharmacokinetics. In the pharmacokinetic study performed in mice, blood samples were obtained over a period of $1 \mathrm{~h}$. The cisplatin concentration from ultrafiltered plasma observed over time is shown in Fig 6. The pretreatment with mifepristone slightly increased cisplatin plasma 
A

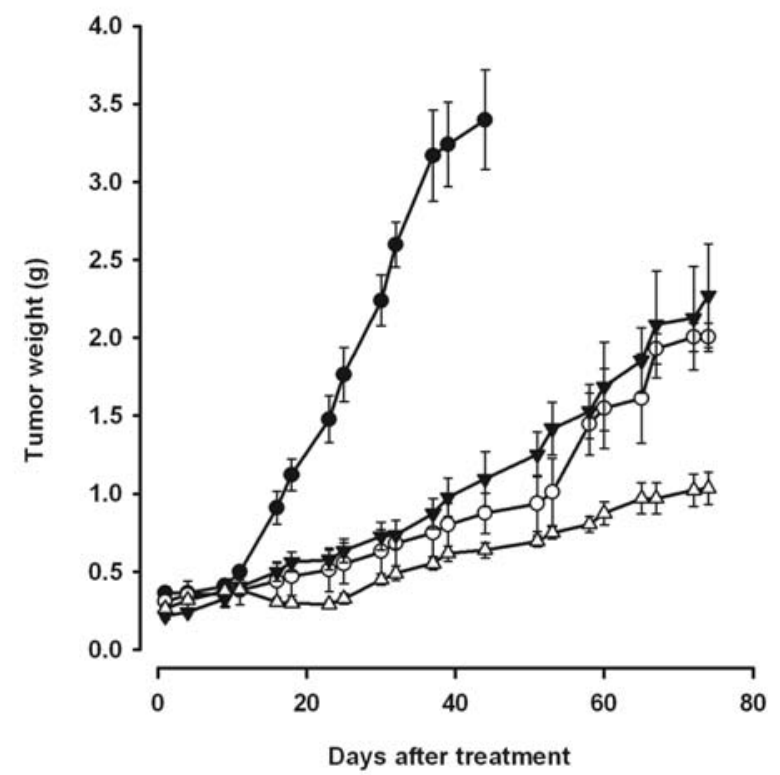

B

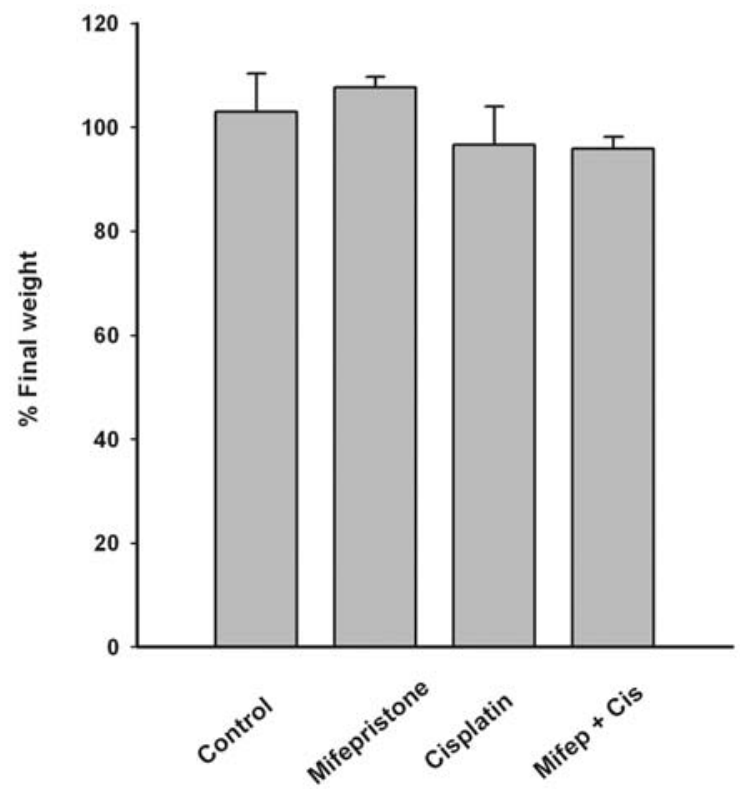

Figure 4. (A) Effect of the combination of cisplatin and mifepristone on tumor weight of cervix xenografts in nude mice. HeLa cells were implanted subcutaneously (s.c.) in the flank of nude mice. Treatment was initiated when the tumors reached $\sim 5 \times 5 \mathrm{~mm}$ (day 0). Cisplatin (o) and mifepristone $(\nabla)$ were administered as single agents and in combination $(\Delta)$. As controls, tumor growth of xenografts from mice treated only with vehicle was determined $(\bullet)$. Tumors were measured using calipers twice weekly for a period of 74 days, and tumor weight were calculated using the formula: weight $(\mathrm{mg})=$ width $(\mathrm{mm})^{2} \times$ length $(\mathrm{mm})$. (B) Final weight of mice treated with single agent cisplatin or mifepristone and combination treatment. There was no significant difference between groups. Data are presented as the means \pm SEM of eight animals.

levels compared to the animals treated with cisplatin alone. The pharmacokinetic parameters of cisplatin are indicated in Table II. After the combined treatment of cisplatin and mifepristone the area under the curve (AUC) and half-life $\left(\mathrm{t}_{1 / 2}\right)$ values increased by 17 and $30 \%$, respectively, whereas that clearance $(\mathrm{Cl})$ value decreased $14 \%$ compared to the animals treated with cisplatin alone.

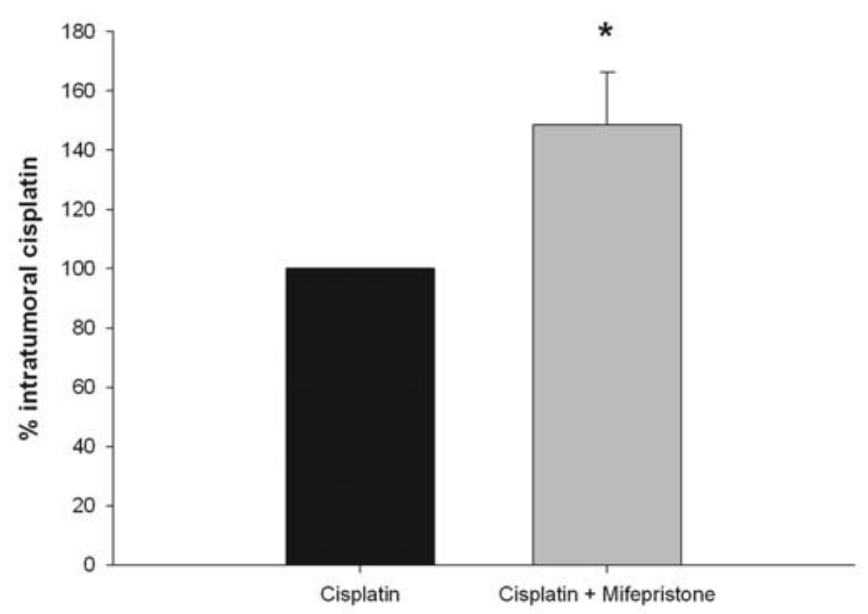

Figure 5. Effect of mifepristone in the intratumoral cisplatin concentration. Mice were injected i.p. with the mentioned schedule in Material and methods. Values are means \pm SEM of eight animals. ${ }^{*} \mathrm{P}<0.05$ compared with cisplatin alone.

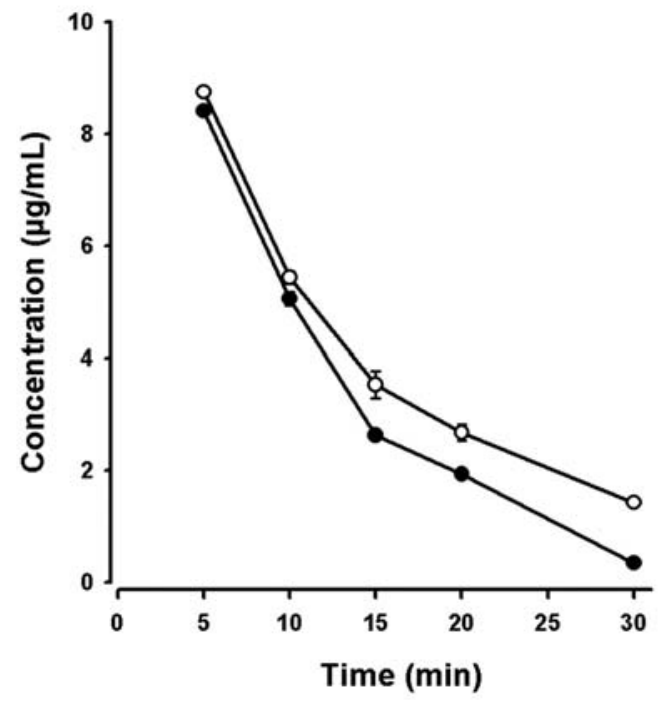

Figure 6. Concentration-time curves of cisplatin in ultrafiltered plasma of nude mice after i.p. dose of cisplatin $(\bullet)$ or after mifepristone-pretreatment (o). Data are represented as mean \pm SEM of three animals.

Table II. Pharmacokinetic parameters of cisplatin in nude mice observed after i.p. administration of $3 \mathrm{mg} / \mathrm{kg}$ dose of cisplatin, or combination with $2 \mathrm{mg} / \mathrm{kg}$ of mifepristone and $3 \mathrm{mg} / \mathrm{kg}$ of cisplatin following the schedule mentioned in methods.

\begin{tabular}{lcc}
\hline Parameter & Cisplatin & Cisplatin + mifepristone \\
\hline AUC & $134 \pm 0.488$ & $157 \pm 0.99^{\mathrm{a}}$ \\
$(\mu \mathrm{g} \mathrm{x} \mathrm{min} / \mathrm{ml})$ & & $8.34 \pm 0.23^{\mathrm{a}}$ \\
$\mathrm{t}_{1 / 2}(\mathrm{~min})$ & $6.4 \pm 0.022$ & $38.28 \pm 0.24^{\mathrm{a}}$ \\
$\mathrm{Cl}(\mathrm{ml} / \mathrm{min})$ & $44.7 \pm 0.163$ & \\
\hline
\end{tabular}

${ }^{\mathrm{a} C}$ Compared with cisplatin group, $\mathrm{p}<0.05$. Data are expressed as mean \pm SEM of four animals. 


\section{Discussion}

Although cisplatin is one of the most commonly used drugs in the treatment of cervical carcinoma, its side effects, such as nephrotoxicity, ototoxicity, neuropathy, mylosuppression and intrinsic or acquired resistance, represent major limitations in its use. The lack of efficacy is generally multifactorial, including reduced drug accumulation, inactivation by thiol containing species, increased repair/tolerance of platinum-DNA adducts, and alterations in the proteins involved in apoptosis. Since pharmacological agents that are able to modulate any of the above parameters could partially restore sensitivity to cisplatin, it is important to identify new compounds able to modulate the cisplatin cytotoxicity in cervical carcinoma, with the aim of improving the effect of chemotherapy with this drug.

No previous data exist on the efficacy of mifepristone in modulating the cytotoxic effects of antineoplastic drugs used to treat human cervical carcinoma. We studied the effect of the combination of mifepristone and cisplatin on two cervical carcinoma cell lines (HeLa and CaSki). These cell lines were chosen for the study because they contain the human papillomavirus (HPV) type 18 (HeLa) and type 16 (CaSki) genotypes. These HPVs have been shown in multiinstitutional studies as etiological agents of cervical cancer and these genotypes account for $>65 \%$ of all HPV DNApositive invasive cervical carcinomas.

The aim of the study was to investigate whether or not mifepristone combined with cisplatin could act synergistically on the cytotoxicity of the latter compound in the treatment of cervical carcinoma. Our in vitro results show that this antiprogestin treatment induces a synergistic cytotoxic effect in HeLa but not in CaSki cells. Whereas HeLa cells are considered one of the most sensitive cervical cancer cell lines to the cisplatin effect, CaSki cells are more resistant to this drug. We found a synergistic cytotoxic effect evident in HeLa cells, with an approximately 2.5 -fold higher potency in comparison to cisplastin alone. However, with CaSki cells there was no significant difference between the treatment with cisplatin alone and the combined treatment. These results may be associated to the fact that HeLa cells have an adenocarcinoma origin and adenocarcinoma tumors are more likely to be hormonally sensitive. Contrary, CaSki cells are derived from an epidermoid tumor metastatic to the small bowel mesentery.

Several studies have demonstrated that mifepristone effectively inhibit the proliferation of certain types of hormone-dependent cancers such as progesterone receptor (PR)-positive breast cancer $(14,15)$, ovarian cancer $(16,17)$, endometrial cancer (18), prostate cancer (19), and gastric cancer (20). However, cervical carcinoma is a type of cancer that does not respond to hormonal treatment. In a previous study, reported by our group, we found that in the cervical cancer cell lines (HeLa, SiHa and CaSki) PR gene levels were relatively low compared to those observed in MCF-7 cells (10). These findings are in accordance with clinical data that show that this type of tumor exhibits low or undetectable levels of both ER and PR, as determined by immunohistochemical and ligand-binding assays (21).
Antiproliferative action of mifepristone has also been reported in ER(-) and PR(-) MDA-231 cells (14), suggesting that the presence of PR may not be required for mifepristone action as a chemosensitizing agent. In HeLa cells which possess an endogenous and functional glucocorticoid receptor (GR) and NF-кB (23), there is the possibility that mifepristone acts through these receptors and their signaling pathways instead of the progesterone receptor, whose expression is very limited in cervical cells.

It is widely accepted that there are distinct effects on GR transcriptional activity by different compounds that bind to GR and induce its nuclear translocation, this is one mechanism of interactions; however, there are others such as the proteinprotein interaction, or the mechanisms of competition for DNA binding sites, physical interaction in DNA, and functional transcriptional induction, some could be signaling pathways to apoptosis (22).

It has also been reported that GR levels in HeLa cells are about 3-fold higher that those in CaSki cells (23). These data are in accordance with our results, in which mifepristone, when combined with cisplatin induce a clear response in HeLa but not in CaSki cells.

We wanted to study the possible mechanism of action of mifepristone as a chemosensitizing agent of cisplatin in a type of cancer without response to hormonal treatment. In this study we determined the effect of mifepristone on the levels of Bcl-2 and Bax expression in presence of cisplatin in HeLa and CaSki cells. The results show that there was no change in the expression of either gene at the dose of mifepristone used.

In the case of antiestrogen resistance in breast cancer, some in vitro and in vivo mechanisms involved in the antiproliferative effects of mifepristone demonstrate that this drug induces growth arrest and cell death by stimulating the activation of caspase- $3,-8$ and -9 in $\mathrm{ER}^{+} \mathrm{PR}^{+}$cells (24). It has been suggested that an antioxidant mechanism is involved in the regulation of endometrial cell proliferation by mifepristone (25). Moreover, apoptosis induction through up-regulation of $\mathrm{NF}-\kappa \mathrm{B}$ binding activity has been reported (26). This early response transcription factor plays an important role in the regulation of genes that are involved in the cascade of events leading to cellular apoptosis (27). The up-regulation of NF-кB in endothelial cells stimulates apoptosis by $75 \%$ (28), as a result of a marked increase in an $\mathrm{NF}-\kappa \mathrm{B}$ activity, there is an overexpression of Bax, a protein that is involved in the promotion of apoptosis. Usually cancer cells present apoptosis inhibition induced by the Bcl-2 oncogene.

In our study the Bcl-2/Bax genes had no change in either cell line. We suggest this is not the only mechanism involved in the cytotoxicity of cisplatin in cervical cancer. It has been reported that steroid hormones may induce physiological effects independent of the hormonal receptors, such as synthesis and expression of cyclin, indicating that a large amount of cells may respond to hormonal actions in the absence of their intracellular cognate receptors (29). This is another mechanism that may be related to the chemosensitivity of cisplatin following exposure to mifepristone in HeLa cells.

On the other hand, there are three known mechanisms by which progestins inhibit the growth of breast tumor cells. 
The first one is the PR mediated cytotoxicity mechanism, which is observed only in $\mathrm{PR}^{+}$cells and takes place with the antagonist. The second one involves cytostatic effects produced by physiological doses of an agonist or antagonist showing inhibition of growth. The third, seen with steroid hormones at high doses, is not a specific cytotoxic effect and may not be mediated by receptors (30).

In an effort to explore the mechanism of action of this antiprogestin on the modulation of cisplatin activity in HeLa cells, we evaluated the intracellular and intratumoral cisplatin accumulation both in the presence and absence of mifepristone. We also measured the plasma levels of cisplatin in order to correlate this to the concentration found in the cells. Our results show that mifepristona increased slightly the plasma levels in cisplatin, which is important since an increase in such levels imply higher intracellular levels of this drug. However, this increase in cisplatin plasma levels is not enough to produce a weight decrease in the animals showing no more toxicity. In fact mifepristone, at a concentration of $10 \mu \mathrm{M}$, which is in the range of the human plasma concentrations observed after a single dose, caused a 2-fold greater retention of cisplatin in vitro, even though this can not be addressed just to the plasma levels but also to the probable decrease of MDR2 detoxifying protein. We also observed an approximately 0.5 -fold increase in the accumulation of cisplatin in the cervical cancer xenograft model, demonstrating that this mechanism is also present in vivo. The dose of mifepristone used in our study was lower than that used by other authors, in which a growth inhibition of ovarian and prostate cancer xenograft was reported with this drug alone. On the other hand with the dose of mifepristone used in the current study, there was no change observed in the weight of the animals, indicating absence of toxic effects.

Another interesting effect has been described for mifepristone that support our results, its ability to modulate the activity of antitumor compounds such as doxorubicin and vinka alkaloids. Additionally, there is evidence that some endogenous compounds such as steroid hormones interact with P-glycoprotein (P-gp) a detoxifying membrane protein (31), and that corticosteroids and mineralocorticoids are substrates for the P-gp transport pump (32). Moreover, some steroid antagonists, such as tamoxifen and toremifen, also interfere with $\mathrm{P}-\mathrm{gp}$ function. These modulating agents are characterized by hydrophobicity and the presence of phenyl rings (33), which are also properties of antiprogestin mifepristone. It has been reported that mifepristone enhances doxorubicin cellular accumulation in resistant human K562 leukemia cells and RHCL rat hepatoma cells (34), suggesting an inhibitory effect on $\mathrm{P}-\mathrm{gp}$ function related to direct interactions with drug binding sites on this molecule, a mechanism of action that has already been demonstrated for other chemosensitizing agents, including verapamil and cyclosporine (35). The increased cisplatin accumulation in our results could be due to a decrease of the specific cisplatin detoxifying protein MRP, but more studies are required to confirm this.

It was reported that mifepristone enhances the chemosensitivity of cisplatin in the resistant ovarian COC1 cancer cell line (36) which is in accordance with another study (37) that showed, in a mouse model bearing xenografted cisplatin- resistant ovarian carcinoma, significantly greater inhibition rates of the tumors when administering the combined treatment in comparison with the application of cisplatin alone.

In summary, we have demonstrated in vitro and in vivo that mifepristone is able to enhance the citotoxicity of some but not all types of cervical cancer cells. This change is related to an increase in the intracellular as well as plasma levels of cisplatin, but not with the Bcl-2/Bax expression ratio. Mifepristone is a promising drug due to the cytotoxic synergistic property. However, more investigations are required on the mechanisms related to its efficacy.

\section{Acknowledgements}

This study was supported by CONACYT (Mexico), grants P44176-M and P44386.

\section{References}

1. Bosch FX: Epidemiology of human papillomavirus infections: new options for cervical cancer prevention. Salud Publica Mex 45: S326-S339, 2003.

2. Lörincz AT: Screening for cervical cancer: new alternatives and research. Salud Publica Mex 45: S376-S387, 2003.

3. Walboomers JM, Jacobs MV, Manos MM, et al: Human papillomavirus is a necessary cause of invasive cervical cancer worldwide. J Pathol 189: 12-19, 1999.

4. Panici PB, Greggi S, Scambia G, et al: High-dose cisplatin and bleomycin neoadyuvant chemotherapy plus radical surgery in locally advanced cervical carcinoma: a preliminary report. Gynecol Oncol 41: 212-216, 1991.

5. Fontanelli R, Spatti G, Raspagliesi F, et al: A preoperative single course of high-dose cisplatin and bleomycin with glutathione protection in bulky stage IB/II carcinoma of the cervix. Ann Oncol 3: 117-121, 1992.

6. Gandara DR, Perez EA, Wiebe V, et al: Cisplatin chemoprotection and rescue: pharmacologic modulation of toxicity. Semin Oncol 18: 49-55, 1991.

7. De Vincenzo R, Scambia G, Benedetti PP, et al: Modulatory effects of tamoxifen and ICI 182,780 on adriamycin resistance in MCF-7 human breast-cancer cells. Int J Cancer 68: 340-348, 1996.

8. Drucker L, Stackievicz R, Radnay J, et al: Tamoxifen enhances apoptotic effect of cisplatin on primary endometrial cell cultures. Anticancer Res 23: 1549-1554, 2003.

9. Tavassoli M, Soltaninia J, Rudnicka J, et al: Tamoxifen inhibits the growth of head and neck cancer cells and sensitizes these cells to cisplatin induced-apoptosis: role of TGF-beta1. Carcinogenesis 23: 1569-1575, 2002.

10. Garcia-Lopez P, Rodriguez-Dorantes M, Perez-Cardenas E, et al: Synergistic effects of ICI 182,780 on the cytotoxicity of cisplatin in cervical carcinoma cell lines. Cancer Chemother Pharmacol 53: 533-540, 2004.

11. Carmichael J, DeGraff WG, Gazdar AF, et al: Evaluation of tetrazolium-based semiautomated colorimetric assay: assessment of chemosensitivity testing. Cancer Res 47: 936-942, 1987.

12. Chou TC: Drug combination: from laboratory to practice. J Lab Clin Med 132: 6-8, 1998.

13. Lopez-Flores A, Jurado R and Garcia-Lopez P: A high- performance liquid chromatographic assay for determination of cisplatin in plasma, cancer cell, and tumor samples. J Pharmacol Toxicol Methods 52: 366-372, 2005.

14. Liang Y, Hou M, Kallab AM, et al: Induction of antiproliferation and apoptosis in estrogen receptor negative MDA231 human breast cancer cells by mifepristone and 4-hydroxytamoxifen combination therapy: a role for TGFß1. Int J Oncol 23: 369-380, 2003.

15. El Etreby MF, Liang Y, Wrenn RW, et al: Additive effect of mifepristone and tamoxifen on apoptotic pathways in MCF-7 human breast cancer cells. Breast Cancer Res Treat 51: 149-168, 1998.

16. Rose FV and Barnea ER: Response of human ovarian carcinoma cell lines to antiprogestin mifepristone. Oncogene 12: 999-1003, 1996. 
17. Rocereto TF, Saul HM, Aikins JA Jr, et al: Phase II study of mifepristone (RU486) in refractory ovarian cancer. Gynecol Oncol 77: 429-432, 2000.

18. Schneider CC, Gibb RK, Taylor DD, et al: Inhibition of endometrial cancer cell lines by mifepristone (RU 486). J Soc Gynecol Investig 5: 334-338, 1998 .

19. El Etreby MF, Liang Y, Johnson MH, et al: Antitumor activity of mifepristone in the human $\mathrm{LNCaP}, \mathrm{LNCaP}-\mathrm{C} 4$, and $\mathrm{LNCaP}-$ C4-2 prostate cancer models in nude mice. Prostate 42: 99-106, 2000 .

20. Li DQ, Wang ZB, Bai J, et al: Effects of mifepristone on proliferation of human gastric adenocarcinoma cell line SGC7901 in vitro. World J Gastroenterol 10: 2628-2631, 2004.

21. Hähnel R, Martin JD, Masters AM, et al: Estrogen receptors and blood hormone levels in cervical carcinoma and other gynecological tumors. Gynecol Oncol 8: 226-233, 1979.

22. Dvorák Z, Vrzal R, Patrick Maurel, et al: Differential effects of selected natural compounds with anti-inflammatory activity on the glucocorticoid receptor and NF-kappaB in HeLa cells. Chem Biol Interact 159: 117-128, 2006

23. Lu YS, Lien HC, Yeh PY, et al: Effects of glucocorticoids on the growth and chemosensitivity of carcinoma cells are heterogeneous and require high concentration of functional glucocorticoid receptors. World J Gastroenterol 11: 6373-6380, 2005.

24. Gaddy VT, Barrett JT, Delk JN, et al: Mifepristone induces growth arrest, caspase activation, and apoptosis of estrogen receptor-expressing, antiestrogen-resistant breast cancer cell. Clin Cancer Res 10: 5215-5225, 2004.

25. Murphy AA, Zhou MH, Malkapuram S, et al: RU486-induced growth inhibition of human endometrial cells. Fertil Steril 74: 1014-1019, 2000.

26. Han S and Sidell N: RU486-induced growth inhibition of human endometrial cells involves the nuclear factor-kappa B signaling pathway. J Clin Endocrinol Metab 88: 713-719, 2003.

27. Barkett $\mathrm{M}$ and Gilmore TD: Control of apoptosis by Rel/NFKappaB transcription factors. Oncogene 18: 6910-6924, 1999.
28. Matsushita H, Morishita R, Nata T, et al: Hypoxia-induced endothelial apoptosis through nuclear factor-kappaB (NFkappaB)-mediated bcl-2 suppression: in vivo evidence of the importance of NF-kappaB in endothelial cell regulation. Cir Res 86: 974-981, 2000.

29. Marino M, Acconcia F, Bresciani F, et al: Distinct non-genomic signal transduction pathways controlled by 17 beta-estradiol regulate DNA synthesis and cyclin (D1) gene transcription in HepG2 cells. Mol Biol Cell 13: 3720-3729, 2002.

30. Horwitz KB: The molecular biology of RU486. Is there a role for antiprogestins in the treatment of breast cancer? Endocr Rev 13: 146-163, 1992.

31. Yang CP, DePinho SG, Greenberger LM, et al: Progesterone interacts with P-glycoprotein in multidrug-resistant cells and in the endometrium of gravid uterus. J Biol Chem 264: 782-788, 1989.

32. Ueda K, Okamura N, Hirai M, et al: Human P-glycoprotein transports cortisol, aldosterone, and dexamethasone, but not progesterone. J Biol Chem 267: 24248-24252, 1992.

33. Hait WN and Aftab DT: Rational design and pre-clinical pharmacology of drugs for reversing multidrug resistance. Biochem Pharmacol 43: 103-107, 1992.

34. Lecureur V, Fardel O and Guillouzo A: The antiprogestatin drug RU 486 potentiates doxorubicin cytotoxicity in multidrug resistant cells through inhibition of P-glycoprotein function. FEBS Lett 355: 187-191, 1994.

35. Ford JM and Hait WN: Pharmacology of drugs that alter multidrug resistance in cancer. Pharmacol Rev 42: 155-199, 1990.

36. Qin TN and Wang LL: Enhanced sensitivity of ovarian cell line to cisplatin induced by mifepristone and its mechanism. Di Yi Jun Yi Da Xue Xue Bao 22: 344-346, 2002.

37. Liu Y, Wang LL and Deng Y: Enhancement of antitumor effect of cisplatin against human ovarian carcinoma cells by mifepristone in vivo. Di Yi Jun Yi Da Xue Xue Bao 23: 242-244, 2003. 